\title{
Twitter as a Social Network in Academic Environments for Exchanging Information Taibah University: A Case Study
}

\author{
Zohair Malki \\ Department of Information and Learning Resources, Taibah University, Saudi Arabia \\ E-mail: zmalki22@gmail.com
}

\begin{abstract}
Twitter is extensively used in the Arab World in the last few years. It showed positive impact on both students and teachers in academic institutions. In this paper we introduce Taibah University as a case study to examine Twitter uses and benefits in education environments. Deans, Students and Teachers accounts on Twitter will be examined to discover the general uses of Twitter and the type of information which is commuting between students and teachers. Results showed that twitter is used extensively in Taibah University for after class room discussions, and for the teachers to share class notes and lectures, in addition it showed highly agreement on the importance of twitter in Taibah University from both students and faculty members.
\end{abstract}

Index Terms-Education, Social Networks, Twitter, Academic Environments.

\section{INTRODUCTION}

In the Arab world and especially in Saudi Arabia, there is a high usage if Twitter by teachers. There are talks on a particular subject include in particular marking "hashtag" on Twitter between teachers and those interested in education. Where all participate distinctive ideas and tips and cooperate and build new relations. There are many teachers who have become famous and followed by thousands of persons, where they considered as inspiring characters and opinion leaders in the area of education [1]

Social networking sites such as Facebook and Twitter offer a portal to information, knowledge, and people, where members can share content and establish relationship with others [2]. Users can share their opinions and respond to others comment on a particular issue or subject area. Features that are available in social networking sites would include user profiles, groups/communities, user blogs, send messages, friends list, user's comments and search features.

In this section, the research objectives are defined and summarized. Then an introduction to Twitter in general will be introduced, we follow that with guidelines for

Manuscript received February 13, 2009; revised July 25, 2009; accepted September 15, 2009.

No. 2006CB303000, No.2007CB316505, corresponding author:Peng Yali how to use Twitter to get the maximum benefit. Finally we introduce an extensive study about Twitter in Saudi Arabia with statistics about the number of users compared to other countries.

\subsection{Research Objectives}

Twitter in Saudi Arabia has been announced as an official communication channel between deans, teachers and students. The objective of this research is to focus on the effect of using Twitter in academic environments such as universities. Taibah University, in Saudi Arabia is taken as a case study. During the second semester of 2014 academic year, random samples from Twitter accounts for Students, Teachers and Deans of Taibah University are selected in multi-stage basis. The accounts will be examined to see what type of information is transferred between users. Study about the general uses of Twitter in Taibah university will be introduced in addition to exploring the effect of using Twitter for both students and teachers.

\subsection{Twitter in General}

It is social media network that allows users to participate, follow or interact with stories, news, views, web links, pictures and videos with a message that does not exceed 140 characters.

It appeared in 2006 as a research project. But today, twitter is phenomenon in the world of social networks with about 500 million users, including presidents, scientists, artists and other famous figures. At the same time the popularity of Twitter continues to gain the momentum. Users in Twitter follow special marks (hash tags) to commute news, photos and personal tweets. [3] The reality is that there is a great lack of Arabic content on the Internet sites in general and in Twitter specifically, there are few Arabic marks (hashtag), which concerned with education, while in the English language, there are a large number of marks (hashtags) that can be followed, for example: \#flippedlesson \#Swann \#edtech \#ECE \#edbkchat \#edchat \#edtools \#elearn \#engchat \#ocw \#openedu.

The use of Twitter comes from two sides, the first is to follow-up and read, where Twitter user follows other user accounts to read their tweets and learn from them, a lot of users stop at this point, for more interaction, users create their own tweets and share it with their followers. 
Twitter is a tool of getting in touch and maybe even starting a conversation with a preferred or admired user, such as a prominent scholar. Chats on Twitter have become increasingly popular in the last year few years [3]

\subsection{Twitter Users in Saudi Arabia}

Over the years, Twitter has grown from a fun media site, initially designed for friends and family members to share small packets of information, to a full-blown professional way of communicating [4].

Twitter has fast become a key player in the field of marketing, communication and business. Even in the field of education it has become an invaluable asset as it allows both students and academics to work together, share their different inputs and gain wider exposure [5].

Many academics are nowadays asking themselves: should we be using Twitter in both in our classroom and for scientific purposes? True enough, Twitter has become one of the main teaching ingredients of online colleges and campuses.

Twitter has a significant importance in professional life for teachers, both in terms of its use as an educational tool or as a means that the teachers use to communicate with each other, in keeping with trends of modern education and its increasing link with the technical world, and the examples for that are many, including the personal learning network (PLN) that are embodied in a model for this fact by providing the opportunity for teachers to access to the latest world standards of education techniques with a view to renew the education away from the stereotypes and classic [6].

A statistic published by business insider by $\mathrm{Bi}$ intelligence research institution, about the analysis of the percentage of the various countries of the world to use social networking sites, which are made through the assessment of large data analysis with respect to the size of the public markets, and analyzing the markets which have potential growth and the demographics.

Statistics indicated that $41 \%$ of Internet users in Saudi Arabia using (Twitter) network and it is the highest proportion of total users in the world, and Indonesia and the Philippines come directly after Saudi Arabia by Close ratio [7].

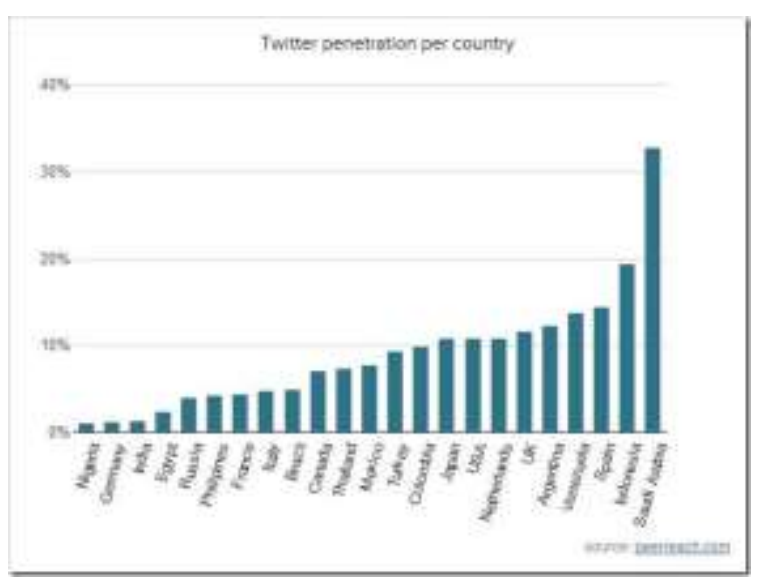

Fig.1. Twitter users traffic, Saudi Arabia has the predominant number of users
Peer Reach in its research found that about the most number of Twitter users in a country came out with a revealing and surprising outcome. It wasn't USA, a country where Twitter was born, neither it was a vastly populated nation like India. Instead it was Saudi Arabia which uses Twitter more than any other country in the world. Figure 1 shows the percentage of country population (y axis) who are using Twitter.

\section{RELATED WORK ON USING TWITTER IN EDUCATION}

Twitter can be put to good use for academic purposes. It helps learn foreign languages In addition it is the perfect way for students to talk to other people from all over the globe, thus helping them to acquire new language skills [8].

Twitter helps students from different classes connect. Students may find it easier to engage in a discussion with fellow students from other colleges if it is done virtually. It is also used to host class discussions; the bashful students who are silent in class may be much more forthcoming and talkative on Twitter [9].

Twitter is used as a writing assignment. It is a good way for students to discover the merits of brevity as you can ask them to write short poems, such as haikus [10] for instance. Twitter and other social media are part of today's professional world. Chances are many of today's students will be using Twitter on a regular basis in their future jobs. Assignments that teach them the basics of online marketing and branding can be of great value [9].

A Twitter wall can also be an opportunity for the shyest of students to voice their opinions and ask questions. It can also be a good way for students to branch out to professionals already renowned for their expertise in their particular field. Students will acquire a different perspective. And it may even lead in the long run to internship opportunities [11].

The positive aspects of Twitter as it also presented an opportunity to deliver collective voice for teachers. But, on the contrary, a worrying trend has appeared, to silence the voice of teachers, as a result, the educational scene has become officials and administrators who found themselves facing the teachers who express their opinions through Twitter, so the administrators have become looking for evidence to punish teachers, believing that their professional status may be affected by what they post [6].

\subsection{Rules for Teachers to Attract Students to Twitter}

As Saudi Arabian government set Twitter as a formal communication channel in academic organizations, a collection of rules for teachers to follow aimed to attract students to use twitter in teaching are presented here, similar rules are presented in [12].

- Do not require students to follow you on Twitter: propose it for your students as an option, and give additional grades for students, remember that not all students use or wish to use a social media site. And remember, if students were obliged to follow you on 
Twitter, they will not continue after the end of the course.

- Commit to post your tweets in certain periods: to increase the added value, post your tweets on certain periods during the week, and do not publish 6 times a day and then wait a week to post again, the possibility that the students read the tweets is more than to be addressed to them at one time.

- Type of the post timing: Do not post in the same timing in a day and remember that the timing of the students may be different from your timing, and Twitter works by showing the latest updates or tweets to followers at some point, and if the students a timing different from yours, you should change the time of the your tweets to suit the timing which they are in and that makes the possibility of seeing updates is bigger.

- Publish links that show friendly content: Do not publish links for content that is specialized for professionals or for high certificates owners, remember who is your audience.

- Set the concerns of your audience: the secret to access the content of the daily life for students is to avoid dry content or which is difficult to access, attach the content with contents that interest your audience and follow it such as: current events and sports.

- Do not re-tweet but post genuine links: the process of re-tweet is good, but your students need to hear from you.

- Suggest people and institutions and magazines to follow: and explain why these accounts are useful for your students, the idea is to encourage the critical thinking and through explaining your choice, you help in building library of considered resources for your students to take advantage of them even in other curriculum.

- Be yourself: give your students a profile of your personality and your interests. And do not be afraid to show your passion and your interests.

- However, avoid many of the highly personalized: focus on the educational material on what is related to it and leave your personal comment for your personal account.

\subsection{Usefulness of Twitter for Teachers and Students}

In the world of rising internet penetration, social media has become an intrinsic part of our daily schedule. Not just for networking, oftentimes they come across as an important medium for gathering knowledge, platform for discussion and a forum for interacting with students in a similar field of study. Twitter ranks high up in the list of educative social platforms that can be used for knowledge expansion. A study by [9] showed that $68 \%$ of students agreed that social media can increase their knowledge. Unlike perception, it is not a site to just follow celebrities but also a very effective academic tool with an exposure to a wide cross section of thoughts and beliefs.

In a study proposed by [13] Twitter today is close to an addiction for many. The need to remain updated is a global phenomenon; teachers and students can make best use of the huge data base of knowledge available. First we show the importance of Twitter for students then we explore the importance of twitter for teachers.

\section{1) Role of Twitter for Students}

For both students and deans alike, this can be a useful source of knowledge gathering as well as trying innovative learning methods. Let's first analyze the kind of impact it can create for the student.

- Expand Knowledge Base: First and foremost decide on your area of interest and kick off your research. What is interesting about conducting a piece of research on twitter is the wide range of alternatives that you could choose from. Not only that you get a superb mix of views and news. There are links to original write ups and articles too which can help you in accumulating all relevant information and fashioning them in your own chosen way.

- Creating Connect: Twitter can help students create a significant base of acquaintances and fellow students who can give you access to many different schools of thought, varied approaches. Not only that, you can also bond with people having similar interests as well as access to many academicians with whom you might not have contact otherwise. Most times even the best minds are relatively more accessible on twitter compared to emails or other conventional ways of establishing contact.

- Ease of Understanding: Twitter is about simplicity. However complex the thought process might be; it has to be expressed in only 140 characters, hence the rush for simplicity and cutting out jargons. The biggest benefit is that whether you are an expert in the chosen field or a new comer, the information that is dissipated is never difficult to grasp.

- Sharing Views: Another interesting way of learning that it is quite popular these days is an active sharing of thoughts. Students can use twitter as a platform to share their views and learn how others are tackling the issue. It helps them get a fresh perspective with an idea on ways to incorporate that in their study matter.

- Exploring new ground: A student's overall academic interest does not finish with some set notes and select reading. Sometimes it becomes very important for the student to read up about new things, understand the other interesting stuff and decide for themselves how they want to go about their chosen filed. This kind of limit less access to new developments, interesting thoughts and revolutionary ideas are all possible only through an active medium like twitter. Also being online surely helps a student save a lot of time and energy and make effective use of the information available.

- Creating platforms for discussion: Not everything and all course material can be found in books. Many topics evolve over cups of coffee, lengthy 
discussions and active ideation. But for most students the classroom could be inadequate for this kind of an exercise. It is here that twitter can usher in a convenient and effective communication module that can help these students get the most of their course material as well as get a sense of how other students are dealing with it and what changes they could afford to incorporate.

\section{2) Role of Twitter for Teachers}

As stated previously, even teachers stand to profit from using twitter as an educative instrument in their daily lectures and make teaching more interesting.

- Introducing topics of discussion: Teachers can look at bringing in a new perspective in their teaching methodology. Instead of reading the study matter and read out verbatim to the students, Teachers can initiate related discussions on twitter and then take forward the course syllabus in accordance to it. Students would feel more involved and might also be more attentive towards the lectures.

- Increasing rate of participation: Also, another interesting aspect is how presence on twitter can stir up interest and also demand. The discussions that you initiate or the views that you might post, will stir up additional interest in your field, and you might end up seeing a lot more people than you expected in the classroom.

- Being Updated: One of the key challenges for any Teachers, is the need to constantly update student's information base and remain ahead of the curve. Given the paucity of time and multiplicity of medium, the twitter is like a one stop shop. Be it sports or literature, science or meta physics, you now have all the information you want right on your fingertips.

- Creating an educational ecosystem: Twitter gives an individual the ability to follow only people they want. So you can make a wide and sensible choice about the areas of interest and type of views you want to follow. With a presence on twitter, communication does not stop. It happens behind closed doors as well as outside in the open. In today's day and era, the only other tool required is a smart cell phone to ensure that the cord of communication is not broken.

In this paper we added a third category, namely Deans. Deans are the responsible persons in Higher education. Dean's responsibility is managing students and teachers affairs, in addition to managing all organization affairs. In the discussion section we studied the role of Twitter for deans and managing stuff.

\subsection{Advantages and Disadvantages of Using Twitter in Education}

The use social media networks such as "Facebook" and "Twitter" and "Google+" as well as "Blogs", has increased over the last few years in the whole world in general and in Arab societies in particular. For example, the estimated number of users of most famous the social media network in the world which is "Facebook" currently has more than 800 million users. As for the Arab world, statistics indicate that the number of users of the "Facebook" is estimated by 32 million users. The estimated number of users of the "Facebook" in Saudi Arabia is about 2.5 million out of 5 million in the Gulf countries, further results can be found in [14].

The role of social media networks is no longer limited to communicate with friends and exchange social and political debates, but its role is much beyond, where several companies have started in exploiting these sites to promote their products and communicate with target audience, as the Governments used it as well to disseminate data and information and receive views and comments by members of the community [15].

As for the academic level, a lot of faculty members in international and Arab universities have begun to use these networks to communicate with the students in order to create transparent and interactive educational environment in which the student is an active element and participates in the responsibility, and not merely a negative recipient for information that the instructor teach in the hall.

The use of social networks in education has many advantages, as stated by [16] including: expanding the circle of learners by providing easy communications between them and the teacher, as well as disseminating the technical culture and expanding students' perceptions by familiarizing them with the latest updates in the field of their studies.

Finally, giving the opportunity to some students, who got shy upon facing the teacher, to express their opinions in written manner, which may help them to be creative. But this could bring social and economic benefits represented in the reduction of expenditure on the classrooms, university buildings, educational tools and instruments, and to reduce the traffic density in the streets of cities, and preservation of the environment by reducing the use of paper and printing.

However, there some defects for using social networks in education. For example, it may be used for the violation of privacy, where there is a personal file for each student contains information about him and his activities and inclinations, and this information could be misused in the case showing them to unreliable persons [17]. As well, the use of the Internet in communication reduces the direct personal confrontation between the teacher and his students, which is important to find a strong sustained relationship between them. One of the important deficiencies is that there may be fraud if the personal file of a student is used by another student, who isn't the owner of the file [18].

Finally, the increase in the number of hours spent by the student in front of the computer may lead to some psychological or social problems.

In spite of these few disadvantages, the advantages seem to be much more, which leads us to believe that the role of social networks in education will continue, and will grow and become more applied and widespread in 
the next few years.

\section{FINDINGS AND DISCUSSIONS}

Every day Twitter users are increasing in Taibah University campus. About 4 years since the university started using Twitter, the number of users exceeded hundreds each year. Twitter has a different audience from Presidents to students. We first introduce analysis of KSA Universities which use social networks, then the research questions are introduced with analysis of the results.

\subsection{Study of Using Social Networks in KSA Universities}

A total of 5 private universities and 28 public universities in Saudi Arabia were surveyed. Out of the 5 private university web sites, $4(80 \%)$ of them are using the selected social media tools. On the other hand, only $13(45 \%)$ of the public university web sites are using, Facebook, Twitter, RSS or blogs.

The most commonly used Web 2.0 tools are Facebook and Twitter. About $18 \%$ of the surveyed university use Facebook while another $15 \%$ use Twitter. Most of the universities (97\%) do not deploy blogs. Only $12 \%$ of the universities use RSS.

However, it can be noted that there are some universities that deploy the social media tools that link back to their respective university accounts. For example, web sites from Dar Al Uloom University, Al Yamamah University, King Saud bin Abdulaziz University for Health Sciences, Qassim University, Islamic University of Medina, Yanbu Industrial College, Al Jawaf University and Taibah University have links pointing back to their respective universities social media accounts.

\subsection{Research Dataset}

Twitter accounts of teachers, students and deans are examined during the second semester of 2014 academic year. We focus on the Twitter accounts by examining them in addition to posting tweets for research purposes and analyzing the reply of the participants. With the word dean, we refer to Taibah university management board member. 33 dean accounts are randomly selected from the available dean accounts. Since there is one to many relationship between accounts and deans or teachers, the deanship account can be used by multiple deans for tweeting and reply to tweets. For single dean he uses his own Twitter account in addition to the deanship account. 230 Twitter accounts are randomly selected from the accounts of twitter for Taibah University students. 70 Twitter accounts for Taibah University teachers are randomly selected.

Multi-Stage Random Sample technique [19] is used for random selection of the accounts. First a collection of collages are selected randomly, then a collection of departments are selected randomly in each collage and finally a collection of student, deans, and teacher accounts are selected randomly in each selected department.

For the purpose of clarification and relevance of each finding, All Twitter accounts are listed with index such as StudentAcc002, DeanAcc031, and TeacherAcc012 when refereeing to Student Account, Dean Account and Teacher Account respectively.

\subsection{Research Question 1}

Question 1: What are the purposes of using Twitter for deans in Taibah University?

\section{1) General Statistics}

There are common similarities in the purposes of using social media tools [20] such as Twitter in KSA universities. When examining the dean's dataset by classifying accounts tweets, we found that Taibah University deans uses Twitter mainly for:

- University Promotions: Promotion of stuff members, such as deans and teachers, general news about the university, sharing of Photos, videos related to the university.

- University Services: Orientation and training programs such searching online databases and OPAC, online guides, Dean of Research in Taibah University introduce training courses to their new stuff academics.

- Outreach: Welcoming messages to students, new staff changes and new appointments

- Online Surveys: Obtaining information via online surveys

Figure 2 shows the general purposes of using Twitter be deans of Taibah University.

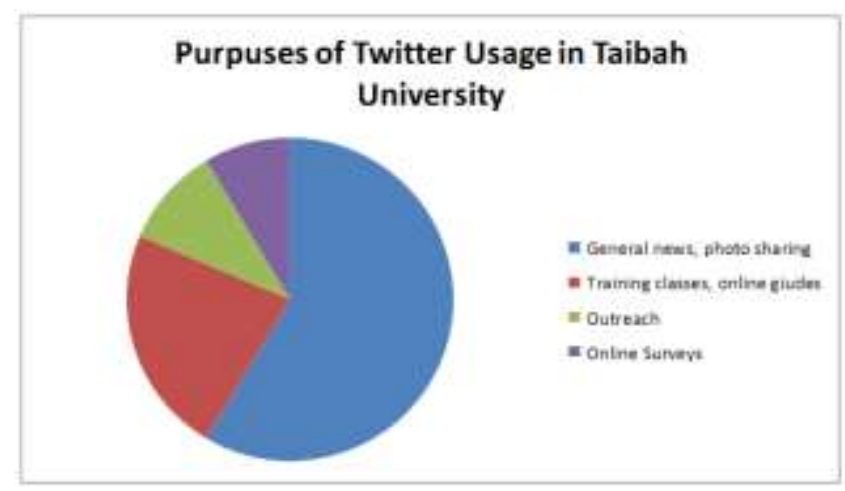

Fig.2. Purposes of using Twitter by deans in Taibah University

In general, Academics and deans at Taibah University use twitter as an important social media tool to stay socially interacted and reliably connected with the university's academic pedagogic concerns [21]. It is noticed that the different deans and departments are continuously updated and connected using 'retweet' option in Twitter.com, so they easily share any important information or announcements and dates of events, activities, or conferences and seminars. The students usually follow and retweet the different departments accounts in Twitter in addition to dean of university and teachers.

\section{2) Statistics for Selected Accounts}


In this section, statistics of selected deans and faculty members' tweets are examined with some reference to most recent updates these tweets' contents. The objective of examining the selected accounts is to explore the uses of Twitter of deans and faculty members in detail.

DeanAcc001 (University President) has 12,700 tweets. He always updates the different college and department activities and conferences and he keeps giving the students pieces of advice, for example in one of his tweets, he has advised the students to work and apply and practice what they learn to make their knowledge fruitful, and 38 students replied thanking him for his nice advice. According to his account statics chart of the retweets he receives there is an average of 81.900 followers $60 \%$ of them are students of Taibah University as shown in Figure 3. He also re-tweets from other sources any good piece of information that has collaboration with Taibah University, either for the students, teachers or university staff. In one of his tweets, he re-tweets from Boudi Club for media an important announcement of the basics Info graphic design workshop.

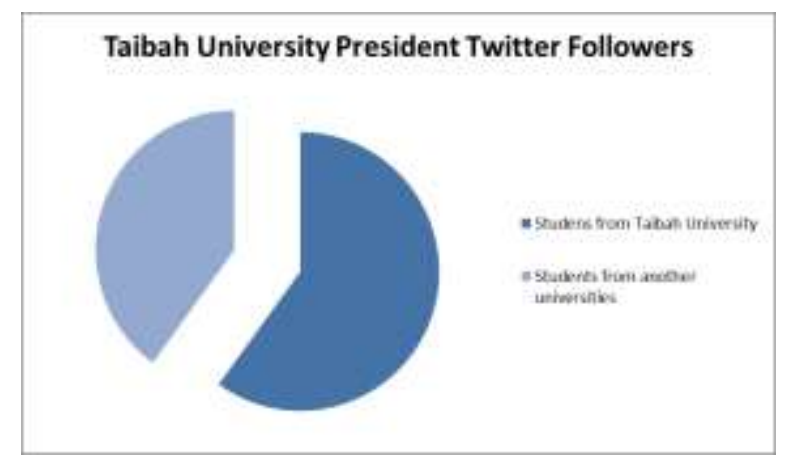

Fig.3. Taibah University President Twitter Followers which showed that $60 \%$ of the followers are from Taibah University, while $40 \%$ of them are from other Universities.

DeanAcc009 (Dean of university studies of female students) has 3523 tweets. They daily inform the students and university staff about the dean and university activities, conferences, seminars and news. The recent tweet that was in 8th December 2014 informed the university staff about the university first aids training offer as and this a good proof that university focus much about different activities. Another tweet from the same dean informed the students that the computer science and engineering college will have Microsoft Day event.

DeanAcc022 (Enrollment and admission dean) has 9043 tweets. This department is concerned with scheduling and organizing timetable of enrollment and admission results. It has an average of 40 re-tweets in every tweet they post and it also has 11.900 followers and $80 \%$ of them are students of Taibah university according to their profiles on twitter .For example, the last tweet from this department was a timetable schedule opening and deadlines for submission of the documents, receiving results for the 1 st \& 2 nd graduates and date of receiving letter of admissions for the students. This recent tweet keeps the students informed about the exact procedures of enrollment at university with all important information.

A member of faculty staff (TeacherAcc011), has 923 tweets .He has good interaction with students and their activities. In one of his tweets, he congratulates business administration team for the big victory they made in handball competition at Taibah University. In another tweet, he posts a live meeting of the university president and faculty members of Business administration department with faculty members of Mara University from Malaysia. He has 749 followers, $60 \%$ of them are his students of Business administration department.

DeanAcc02 (The official twitter account of Taibah university) has 3178 tweets and 35,000 followers, $60 \%$ of them are students, $30 \%$ of university staff and faculty members .It informs the students with all new updates different kind of activities and academic seminars and conferences of all Taibah University departments. For example, in one of its tweets, they show the timetable and the procedures of enrollment in the 6th scientific conference. Table 1 shows the number of Tweets and followers for the above dean accounts. From Table 1, the account with the highest number of followers is DeanAcc001 which is the university president. This is due the fact that most of the problems of any member in the university can be solved by directly connecting the university president. The second is DeanAcc022, account of the Enrollment dean. The number of followers is high due to the fact that most discussions or tweets are those for persons asking for enrolment mostly from outside the university; whether they are enrolled or not, they keep following the Enrollment account. This also is reflected in the number of tweets for that department which comes in the second order after university president account.

Table1. Taibah university teachers and deans followers and tweets

\begin{tabular}{|l|c|c|}
\hline Name & $\begin{array}{c}\text { Number of } \\
\text { Tweets }\end{array}$ & $\begin{array}{c}\text { Number of } \\
\text { followers }\end{array}$ \\
\hline DeanAcc001 & 12,700 & 81,900 \\
\hline DeanAcc009 & 3523 & 11,900 \\
\hline DeanAcc022 & 9043 & 70,470 \\
\hline DeanAcc002 & 3178 & 35,000 \\
\hline
\end{tabular}

Generally, over $50 \%$ of Taibah university students, faculty members, department and dean collaborate via social media such as Twitter to have more connectivity and better communication that would positively influence the progressive development of this university. It also keeps every member of university either student, faculty members, teachers or even university staff members up to date of the university activities, time tables, and different organized seminars.

\subsection{Research Question 2}

What Type of Information is transferred between Deans, Students and Faculty members?

In Taibah University, there is increasing number of teachers who uses twitter to communicate with students. We found that more than $90 \%$ of students and teachers use Twitter for academic communications. After analyzing twitter accounts for the teachers, we found that most of the teachers have already realized that twitter is a perfect helper. The teacher reminds students about homework, report seminars, webinars or changes in time- 
table and publishes the tips and tricks that automatically come to them on the phone. The main advantage for teachers is that they don't need to know student's telephone number.

Figure 4 shows what are the most tweets that teachers, students and deans in Taibah University made together with the type of tweets.

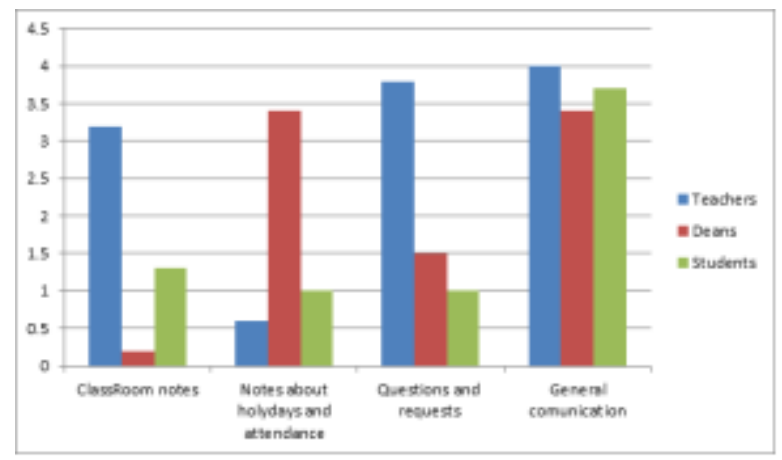

Fig.4. Information which is transferred between Twitter users in Taibah .University

From Figure 4, class room notes are sent mostly by teachers, however students also send some notes which is collected from the lectures. Deans participate to sending class notes by notifying users of cancelled classes due to holidays. Some notes about holidays are sent by teachers. However, as shown in the figure, deans are sending the largest number of tweets regarding holidays and attendance. The student questions are less than that for the teachers. The posted questions are focused on homework's and study martials. The students post questions regarding the exam questions style and the important topics of the teacher's subject. The general communications are approximately similar for deans, students and teachers.

Twitter is used for developing the skills of summarization. For example, TeacherAcc121 asks students to read an article or a chapter from a book about QoS in video transmission, and enforce students to publish a brief summary of the text's main ideas. The limit of 140 symbols in twitter post developed the ability of the students to express their thoughts briefly and clearly enough.

A group of students, namely, StudentAcc125, StudentAcc130, StudentAcc131, StudentAcc035 and StudentAcc 040 are working on the same graduate project, they use twitter to exchange the latest results, ideas and to organize a brainstorming.

The student group observes and shares the latest information about new books, articles and scientific papers through twitter. The group knows how difficult it is to find a teacher at the university. The lack of the official communication per the Internet helps the group to feel less constrained.

StudentAcc201 uses Twitter to learn new language, the student follow many Italian accounts without the mutual consent of account users. This way the student has an access to a language content that he like to learn.

To sum up, We found that Twitter is used as a tool to generate thoughts and ideas and a convenient platform for discussing, for example, graduate projects or just to find the information. It is also used as a tool for learning new language.

\subsection{Research Question 3}

What are the benefits to students when Twitter is used by Faculty members?

The benefits for students when Twitter is used by Faculty members are presented here.

- Learning New Language: TeacherAcc016 uses twitter as a tool for teaching new language as follow: he asks students questions in a foreign language (English) and asks them to answer in the same language or translate their tweets into their own language (Arabic). By examining teacher accounts, we found that $82 \%$ of Foreign language teachers in Taibah University uses Twitter for learning the related language.

- After-class discussions with the students: Simply because the class is over does not mean that the students have to stop learning. For example TeacherAcc017, TeacherAcc018 and TeacherAcc018 in addition to 40 Teacher accounts (57\%) use Twitter to ask questions about their latest lectures. Teachers create an online community where students hold debates and academic discussions. StudentAcc199 in one of his tweets stated that the teacher's online community built a sense of friendship and help him in his studies.

- Classes and Lectures Latest News: Teachers and deans (For example TeacherAcc26, TeacherAcc27 and DeanAcc23) use Twitter for sharing general information about the class, such as deadlines, exam dates and all other related forms of announcements for the students. They obtained feedback from students that allow them to get their students reactions on lectures, readings and tests. They also used Twitter to publicize general information about events such as symposiums and book releases. TeacherAcc29 linked Twitter to Blackboard. By adding a Twitter widget to the class Blackboard site, the teacher got more increasing number of interacting students. Blackboard is easy to use software for class management. In this way students are kept updated with the latest class news.

- Strengthening Relationships: Strengthening the relationship teachers and deans have with the students as the discussions on Twitter are less formal and more casual.StudentAcc78 stated that he can contact directly with his Statistics teacher through Twitter, before using Twitter, he tardily contact with the teacher.

\section{CONCLUSION}

Twitter is an official tool for communication in academic environments. We studied the effect of using Twitter in Taibah University. Results showed that more 
than $90 \%$ of students and teachers use Twitter as a teaching tool for communication and after class support. Taibah university students uses Twitter as a tool for teaching new language. Deans use Twitter to organize training courses, seminars and university stuff promotions. Future work will concentrate on using social media in education and the effect of social networks on enhancing education level. The study will cover both universities and schools in addition to teachers. Feedback from student's parents will be obtained to screen the behaviour of the students in using social media in education.

\section{REFERENCES}

[1] Rindra M Ramli, "A Study on the use of Facebook, RSS, Blogs and Twitter (Web2.0)" QScience Conference Proceedings, March 2014.

[2] Kroski, E. "Web 2.0 for librarians and information professionals:" Neal-Schuman Publishers, Inc.2008

[3] Andrea Broughton, Beth Foley, Stefanie Ledermaier and Annette Cox, "The use of social media in the recruitment process" Acas research publications 2013.

[4] Mello, J. P. How social media performed during Aurora tragedy. PCWorld. Retrieved from http://www.pcworld.com/article/259629/how_social_medi a_performed_during_aurora_tragedy. html(2012, July).

[5] Li, C., \&Bernoff, J. Groundswell: Winning in a world transformed by social technologies. Boston, MA: Harvard Business School Publishing. (2008).

[6] Vincent Cho, Jina Ro, and Josh Littenberg-Tobias "What Twitter Will and Will Not Do: Theorizing About Teachers' Online Professional Communities" LEARNing Landscapes Vol. 6, No. 2, pages 45-62 Spring 2013.

[7] Hindu, "Saudis world's most active Tweeters, Indians 21st: study" Online Nov. 2014

[8] Esra Harmandaoglu "The Use of Twitter in Language Learning and Teaching" International Conference on ICT for language learning, ICT2012, Turkey, April, 2012.

[9] Lee Andrew Dunn, "Teaching In Higher Education: Can Social Media Enhance The Learning Experience?”.University of Glasgo technical reports, 2013.

[10] Sandy Stokely "Haiku and Beyond: A Study of Japanese Literature", El Alma de la Raza Series, Denver Public Schools, 2000.

[11] Jeff Dunn "100 Ways To Use Twitter In education, By Degree Of Difficulty" Edudemic connecting education and Technology, April 25, 2012.

[12] Dunlap, J. C. \& Lowenthal, P. R. Tweeting the night away: Using Twitter to enhance social presence. Journal of Information Systems Education, 20(2). (2009).

[13] Perez, S.. Who Uses Social Networks and What Are They Like? (Part 2). Retrieved January 2010, from ReadWriteWeb: http://www.readwriteweb.com/archives/ who_uses_social_networks_and_what_are_they_like_part 2.php (2009, July 9).

[14] Fadi Salem, Racha Mourtada "Social Media in the Arab World: Influencing Societal and Cultural Change?", Dubai School of Government, Arab Social Media Report, Vol2, No. 1 July 2012.

[15] Trubitt, L., \&Overholtzer, J. Good Communication: The Other Social Network for Successful IT Organizations. EDUCAUSE Review, 44 (6), 90-92, 94, 96, 98, 100. (2009).

[16] Harris, A., \& Rea, A. "Web 2.0 and Virtual World Technologies: A Growing Impact on IS Education".
Journal of Information Systems Education, 20 (2), 137144. (2009).

[17] Laura Smith-Spark, Samya Ayish "Saudi prince: Blocking social media platforms is a 'losing war' " $\mathrm{CNN}$, May 7, 2013.

[18] Sanja Kelly, Sarah Cook, Mai Truong "FREEDOM ON THE NET 2012: A Global assessment of Internet and Digital Media", Freedom House, September 24, 2012

[19] Kalsbeek, W., O.M. Mendoza and D.V. Budescu Cost models for optimum allocation in multi-stage sampling. Survey Methodology, vol. 9, No. 2, pp. 154-177. (1983).

[20] Asad Mehmood, Abdul S. Palli, M.N.A. Khan "A Study of Sentiment and Trend Analysis Techniques for Social Media Content” IJMECS Vol. 6, No. 12, December 2014

[21] Harish Kumar V,Arti Arya,Divyalakshmi V,Nishanth H S "Artificial Neural Network in Prognosticating Human Personality from Social Networks" IJMECS Vol. 5, No. 8, October 2013.

\section{Authors' Profiles}

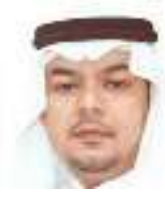

Zohair Malki: Working at the Department of Information and Learning Resources, Taibah University, Saudi Arabia. Currently he is the dean of the collage of Computer Science and Engineering in Yanbu, his research interests include, E-learning and education techniques; using ICT in education, computer technology, and computer software and algorithms.

How to cite this paper: Zohair Malki,"Twitter as a Social Network in Academic Environments for Exchanging Information Taibah University: A Case Study", International Journal of Information Technology and Computer Science(IJITCS), vol.7, no.10, pp.15-22, 2015. DOI: 10.5815/ijitcs.2015.10.03 